1) Bei Abwesenheit von Wasser findet an blanken Glasflächen, mögen dieselben alkalihaltig, oder durch Behandlung mit siedendem Wasser an ihrer Oberfläche selbst alkaliarm gemacht worden sein, überhaupt keine Condensation oder merkliche Adsorption des zugeleiteten und dadurch mit den betreffenden Flächen in Berührung gebrachten Gases statt, und zwar weder im ersten Augenblick, was über Bunsen's Resultat hinausgeht, noch im Laufe der Beobachtungszeit.

2) Wird den von Feuchtigkeit völlig befreiten Glasfäden Wasser zugeführt, so stellt sich sofort eine Verdichtung von Gas an der Glasoberfäche ein, und zwar ist dieselbe an der alkalireichen Oberfläche bei weitem stärker als an der alkaliärmeren. In beiden Fällen ist die Condensation in den ersten Minuten eine lebhafte.

3) Die auf der alkalireichen Oberfläche von Glasfäden zurückgehaltene, bei der betreffenden successive erhöhten Temperatur nicht verdampfbare Wassermenge ist grösser als bei denjenigen Glasfäden, welchen durch Behandlúng mit siedendem Wasser an der Oberfläche Alkalien entzogen worden sind. Ferner gelingt es in kürzerer Zeit, namentlich bei niederen Temperaturen, die Feuchtigkeit durch einen trockenen Luftstrom von den mit Wasser gekochten Fäden zu entfernen.

\title{
Eine Tabelle der Spannung des Wasserdampfs über wässriger
} Aetzkalilösung hat G. Errera*) berechnet. Dieselbe soll speciell für den Gebrauch bei der Dumas'schen Stickstoffbestimmungsmethode dienen. Ich kann dieselbe hier nur erwähnen.

Zur Trennung schwer filtrirbarer Niederschläge von der Flüssigkeit schlägt E. Ba u e $\left.{ }^{* *}\right)$ vor, die Lösung durch Diffusion zu entfernen. $\mathrm{Zu}$ diesem Zweck benutzt man einen Trichter ohne Stiel, der unten nach ziemlich weit abgeschliffen ist, so dass die Spitze eines eingesetzten Filters unten herausragt. Setzt man den so vorbereiteten Trichter auf ein Gefäss mit Wasser, in welches das Filter eintaucht und füllt die Flüssigkeit sammt Niederschlag ein, so wird die Lösung gegen das Wasser diffundiren und durch mehrmalige Erneuerung des Wassers schliesslich ganz entfernt werden.

Apparate zum raschen und genauen Abmessen von Flüssigkeiten sind von G. P. Vanier***) und von B. Gerdes $\dagger$ ) angegeben worden. 13, 213.

*) Gaz. chim. it. 18, 225; durch Beibl. zu den Annal. der Phys. und Chem.

**) Chemikerzeitung 12, 789 .

***) Journal of analytical Chemistry 2, 144 .

†) Chemiker-Zeitung 12, 1109. 